\title{
Availability of personnel, facilities and services in Primary Health Care Centres in a Local Government Area in Benin City, Nigeria
}

\author{
Vincent Yakubu Adam, ${ }^{1,2}$ Joy Chinyere Nwaogwugwu ${ }^{1}$ \\ ${ }^{1}$ Department of Community Health, University of Benin Teaching Hospital, Benin City, Nigeria; \\ ${ }^{2}$ Department of Community Health, University of Benin, Benin City, Nigeria
}

\begin{abstract}
Background: Effective delivery of healthcare services especially at the Primary Health Care level requires availability of ade-
\end{abstract}

Correspondence: Vincent Yakubu Adam, Department of Community Health, University of Benin Teaching Hospital, PMB 1111, Benin City, Edo State, Nigeria.

Tel.: +234 8023327951

E-mail: vincent.adam@uniben.edu

Key words: Primary Health Care; Primary Health Centres; personnel; facilities; services; availability; local government area; Benin City; Nigeria.

Acknowledgements: The researchers thank the management and staff of Egor Local Government Area for their cooperation during the study. The technical support of the Department of Community Health, University of Benin Teaching Hospital is also well acknowledged.

Contributions: VYA: Conception, design, manuscript drafting, revision and final approval, JCN: Data collection, statistical analysis, literature review and manuscript drafting.

Conflict of interest: The authors declare no conflict of interest.

Funding: None.

Ethics approval and consent to participate: Ethical approval to carry out the study was obtained from the Ethics and Research Committee of University of Benin Teaching Hospital, Benin City, Nigeria. Permission to carry out the study was granted by the Chairman of Egor Local Government Area through the Medical Officer of Health of the Local Government Area. Verbal informed consent was obtained from the Heads of the Primary Health Care facilities after explaining the purpose of the study to them. They were also informed that their participation in the study was voluntary and that they could opt out of the study at any time.

Consent for publication: Verbal informed consent was obtained from the heads of PHCs.

Availability of data and materials: The authors hereby declare that they will make available data and materials used for the preparation of the manuscript upon request.

Received for publication: 23 September 2020.

Revision received: 12 October 2020.

Accepted for publication: 12 October 2020.

This work is licensed under a Creative Commons Attribution NonCommercial 4.0 License (CC BY-NC 4.0).

CC Copyright: the Author(s),2020

Licensee PAGEPress, Italy

Annals of Clinical and Biomedical Research 2020; 1:111

doi:10.4081/acbr.2020.111 quate infrastructure, basic diagnostic medical equipment, drugs and well-trained medical personnel. Quality Primary Health Care initiatives have been recognized as fundamental to improving health outcomes. This study assessed the resources available for Primary Health Care delivery in a Local Government Area in Benin City, Nigeria.

Materials and Methods: This was a descriptive cross-sectional study. All the public primary health centres in Egor LGA, Benin City, Nigeria were assessed for availability of personnel, facilities/equipment and services using an adapted observational checklist.

Results: All the 10 public primary health centres were assessed. The primary health centres had inadequate skilled-manpower: only $1(10.0 \%)$ had a medical officer, Community Health Officers and nurse/midwives were adequate in only $2(20.0 \%)$, and none of them $(0.0 \%)$ had a medical record officer and pharmacy technician. Basic equipment for examination of clients were available in 3 of the health facilities $(30.0 \%)$. All 10 of the health centres $(100.0 \%)$ offered basic services but not for 24 hours. Essential drugs were not regularly available in all the facilities.

Conclusions: Basic healthcare services were rendered but not for 24 hours. Several challenges such as inadequate skilled health personnel, lack of basic amenities, and shortage of essential drugs affect the primary health centres. Basic hospital facilities/equipment needed to enhance 24 hours' service delivery at the primary health centres should be provided by the Local Government.

\section{Introduction}

Primary Health Care (PHC) is the cornerstone of a country's healthcare system. It is the closest level of healthcare to individuals, the family, and the community as enshrined in the National Health Policy. ${ }^{1,2}$ Effective delivery of healthcare services requires availability of adequate infrastructure, basic diagnostic medical equipment, drugs and well-trained medical personnel. Quality PHC initiatives have been recognized as fundamental to improving health outcomes. ${ }^{3,4}$ Strengthening PHC is the most inclusive, effective and efficient approach to enhance people's health and well-being. PHC is the cornerstone of a sustainable health system for universal health coverage and health-related Sustainable Development Goals (SDGs), especially SDG 3, which is to ensure healthy lives and promote well-being for all at all ages. There is need for equity and efficiency in healthcare service delivery, through provision of technical and financial supports to healthcare facilities at all levels of administering services. ${ }^{4,5}$ To effectively manage health services and achieve good quality of care, standards have to be put in place. ${ }^{6,7}$ The Ward Health System (WHS), which is the strategic thrust for the delivery of PHC services in Nigeria was introduced by the National Primary Health Care Development Agency (NPHCDA) in 2000 in order to improve health, sustain effective and efficient PHC service delivery at the electoral ward 
level. In addition, to ensure effective delivery of PHC services, the Ward Minimum Health Care Package (WMHCP) was developed with the aim of providing the wards with a minimum set of health services needed to meet the basic health requirements of households towards achieving the global target of "Health for All" at low cost. ${ }^{4,6,7}$ To facilitate this, effective integration of all PHC services under one authority is needed in order to reduce fragmentation in the delivery of PHC services, thus bringing Primary Health Care Under One Roof (PHCUOR). 8,9

The National Health Act (NHAct) of 2014 provides the legal framework required for the attainment of Universal Health Coverage (UHC) through PHC in Nigeria. ${ }^{10}$ This is also emphasized in the National Strategic Health Development Plan II (NSHDP II). ${ }^{11}$ The Edo State Strategic Health Development Plan II which is also in conformity with that of the national focuses on PHC as the bedrock of healthcare service delivery including linkages of service delivery through referrals to existing secondary care facilities especially general hospitals. ${ }^{12}$

The provision of healthcare at PHC level is largely the responsibility of local governments with the support of State Ministries of Health in Nigeria. Staff salaries, facility construction and maintenance, including supply of drugs, equipment and other medical commodities are all predominantly provided by local governments, mainly funded from statutory allocations received from state government revenues. ${ }^{9}$

The delivery of healthcare at the primary level has been faced with many challenges in Nigeria, thus affecting efforts to reduce the burden of communicable and non-communicable diseases in the communities, including the reduction of the high maternal, newborn and child morbidity and mortality. The challenges include: inadequate staffing and inequitable distribution of healthcare workers, low morale of workers due to irregular and unpaid salaries, poor working conditions including lack of basic amenities, lack of water and electricity supply, inadequate supply of essential drugs and its consequence constraint on service delivery, weak governance system and multiple lines of command or authority, inadequate and dilapidated infrastructure, poor sanitary and waste management system, as well as poor community participation and ownership. ${ }^{13,14}$ This study tried to ascertain the availability of personnel, facilities and services in PHC centres in Egor LGA, Benin City, Nigeria. It is hoped that the findings of the study will enable evidenced-based decision-making by policymakers and programme implementers to improve and strengthen Primary Health Care System in the study locale and Nigeria.

\section{Materials and Methods}

This descriptive cross-sectional study was conducted in Egor LGA, one of the 18 LGAs in Edo State, Nigeria with its administrative headquarters in Uselu. The LGA, which consists of 10 electoral wards, is located in Edo South Senatorial Zone and is bounded to the North by Ovia North East LGA, to the East by Ikpoba Okha LGA, to the south by Oredo LGA and to the West by Ovia South-West LGA. The 10 wards in the LGA include: Ugbowo, Okhoro, Uwelu, Uselu I, Uselu II, Ogida I, Ogida II, Useh, Egor and Evbotubu. The total area of the LGA is $93 \mathrm{~km}^{2}$ with a population of 340,287 at the 2006 national census ${ }^{14}$ and a projected population of 516,986 by 2020 . The health facilities present in the LGA include: 10 public Primary Health Care Centres, University of Benin Teaching Hospital (UBTH), and several private hospitals. Majority of the inhabitants of Egor LGA are civil servants, students, artisans and traders. ${ }^{12}$
Data was collected from all the 10 public Primary Health Centres (PHCs) in the LGA. The PHCs are located in the following wards in the LGA Namely: Egor, Evbotubu, Ogida I and II, Okhoro, Useh, Uselu I and II and Uwelu. Ugbowo, which is also one of the wards in Egor LGA, does not have a PHC facility. A qualitative tool was used for data collection - a PHC checklist adapted from the NPHCDA PHC guidelines/minimum standards for PHC. ${ }^{6,7}$ The adapted tool, which was divided into three sections, was used to assess the availability of personnel, facilities/equipment, and services in PHCs in Egor LGA, Benin City, Nigeria. The information needed from the PHC facilities were obtained from the Heads of the PHCs. The data collected are presented in form of frequency tables.

Ethical approval to carry out the study was obtained from the Ethics and Research Committee of UBTH. Permission to carry out the study was granted by the Chairman of Egor LGA through the Medical Officer of Health of the LGA. Verbal informed consent was obtained from the Heads of the PHC facilities.

\section{Results}

Table 1 shows that half, 5(50\%), of the PHC facilities in Egor LGA had perimeter fences with sign posts. Potable water supply was also available in $5(50 \%)$ of the health facilities. Only $1(10 \%)$ of the PHCs is connected to the national grid for power supply. Though, 9 (90\%) of the PHCs had the required number of rooms, only $2(20 \%)$ had staff accommodation. Basic examination and diagnostic equipment like stethoscope, sphygmomanometer and thermometer were found in a third of the facilities. None of the PHCs had adequate delivery rooms, maternity beds and pharmacy/drug dispensing units.

Table 1. Infrastructure/equipment available in PHCs in Egor LGA.

\begin{tabular}{lcc}
\hline Parameter & $\begin{array}{c}\text { Frequency } \\
(\mathrm{n}=\mathbf{1 0})\end{array}$ & Percent \\
Sign post (visible from entry \& exit point) & 5 & 50.0 \\
Perimeter fence & 5 & 50.0 \\
\hline Security post & 4 & 40.0 \\
Power supply (connected to national grid) & 1 & 10.0 \\
\hline Water supply (from motorized borehole) & 5 & 50.0 \\
Pest control services (fumigation) & 0 & 0.0 \\
\hline Windows (screened with net) & 2 & 20.0 \\
Pharmacy and dispensing unit & 0 & 0.0 \\
\hline Delivery room (2) & 0 & 0.0 \\
Maternity bed (10) & 0 & 0.0 \\
\hline Emergency bed & 3 & 30.0 \\
Roof (good condition) & 8 & 80.0 \\
\hline Basic diagnostic equipment (stethoscope, & 3 & 30.0 \\
sphygmomanometer, thermometer) & & \\
Soap/disinfectant dispenser & 10 & 100.0 \\
\hline Door name plate & 2 & 20.0 \\
Staff accommodation (2 units of 1 bedroom flats) & 2 & 20.0 \\
\hline Number of rooms (13) & 9 & 90.0 \\
Toilet facility (male \& female) & 10 & 100.0 \\
\hline Waste disposal site (sanitary) & 0 & 0.0 \\
\hline
\end{tabular}


In Table 2, all the PHCs in Egor LGA (100\%) had adequate Community Health Extension Workers (CHEWS) and Health Attendants. Other healthcare workers such as: Medical Officers (doctors) -1 (10\%); Community Health Officers (CHOs) -2 (20\%); Nurses/Midwives - 2 (20\%) general maintenance staff - 2 $(20 \%)$ were inadequate. Pharmacy technicians, medical records officers, environmental officers and required number of security personnel were absent in all the PHCs.

In addition, Table 3 shows that all $10(100 \%)$ of the PHCs in Egor LGA offered basic medical services except oral health and community mental. Essential drugs were not regularly supplied in all the $10(100 \%)$ facilities and none of them rendered 24 hours' service. Only half of the PHC facilities in Egor LGA 5 (50\%) offered HIV testing and counseling services.

\section{Discussion}

Primary Health Care is a grass-root approach towards universal and equitable health care for all. The strategy is meant to address the main health problems in the community, providing promotive, preventive, curative and rehabilitative services. ${ }^{15}$ It is laudable that all the public PHC facilities in Egor LGA provide basic health care services to members of its populace including: maternal, newborn and child health services, family planning, immunization, malaria and HIV testing services, including malaria control and other curative services. This will assist greatly in reducing the disease burden especially among the vulnerable groups in the population. The maternal and child health services will ensure access to a continuum of care for women during antenatal, perinatal and postnatal period, which is critical for the survival of women, newborn and children. ${ }^{16}$ However, some core elements of Primary Health Care such as regular provision of essential drugs, community oral health and community mental health services were lacking. In addition, the HIV/AIDS Testing Services were not available in all the primary health centres. These could be as a result of poor political will and poor funding of the Primary Health Care System by the Local Government Management or due to lack of skilled health personnel to provide the services that are absent. These would increase the burden of health care delivery at the secondary and tertiary levels of care.

Though most of the PHCs had more than the required number of CHEWs, it is worrisome that other skilled health workers such as medical officers, $\mathrm{CHOs}$ and nurses/midwives were inadequate. A study done in Edo North Senatorial Zone in Nigeria had a similar finding. ${ }^{17}$ Inequitable distribution of health personnel in some PHCs will reduce the efficient delivery of healthcare services leading to reduced facility utilization and loss of clients/patients to follow up. The Local Government Commission should ensure that diverse skilled health workers are employed and appropriately deployed in order to reduce the inequitable distribution of health personnel in the Primary Health Care System. In addition, pharmacy and laboratory technicians, including medical records personnel, should be employed to improve provision of quality health care, reduce the workload on existing PHC staff, and promote access to health care at the primary level of care.

Also, all the PHC facilities had irregular supply of essential drugs, inadequate basic diagnostic tools, and equipment for provision of some essential maternal, newborn and child health services were not available. Delivery rooms and maternity beds were lacking, while emergency beds including accommodation for skilled healthcare workers were inadequate in the health facilities. In addi- tion, the health services provided at all the PHC facilities were not rendered for 24 hours due to issues related mainly to insecurity such as lack of perimeter fence, security posts and personnel, including lack of power supply from the national grid. All the problems observed in the PHCs will reduce availability of comprehensive health service delivery to community members. A similar result was observed in a study done in Calabar, Nigeria. ${ }^{18}$ Inadequacy of skilled health personnel, irregular supply of essential drugs and poor health services in the PHCs will limit the provision of optimal healthcare delivery and are documented barriers to satisfactory utilization of health facilities by community members. ${ }^{19}$ This may enhance the patronage of alternative healthcare providers such as patent medicine vendors/stores, spiritual homes and even traditional birth attendants with possible poor outcomes like complicated health conditions and increased mortality. Low budgetary allocation and investment in health including poor political will and the non-availability of skilled personnel for employment at the PHC level might be responsible for the short supply or

Table 2. Health personnel available in PHCs in Egor LGA.

\begin{tabular}{lcc} 
Ideal number of personnel(s) & $\begin{array}{c}\text { Frequency } \\
(\mathrm{n}=\mathbf{1 0})\end{array}$ & $\begin{array}{c}\text { Percent } \\
\text { Medical officer (if available) }\end{array}$ \\
Community Health Officer (1) & 2 & 10.0 \\
\hline Nurse/midwife (4) & 2 & 20.0 \\
Community Health Extension Worker (CHEW) (3) & 10 & 20.0 \\
\hline Junior CHEW (6) & 3 & 300.0 \\
Environmental Officer (1) & 0 & 0.0 \\
\hline Pharmacy technician (1) & 0 & 0.0 \\
Laboratory technician (1) & 0 & 0.0 \\
\hline Medical records officer (1) & 0 & 0.0 \\
Health Attendant/Assistant (2) & 10 & 100.0 \\
\hline Security personnel (2) & 0 & 0.0 \\
General maintenance staff (1) & 2 & 20.0 \\
\hline
\end{tabular}

Table 3. Services available in PHC facilities in Egor LGA.

\begin{tabular}{lcc} 
Parameter & $\begin{array}{c}\text { Frequency } \\
(\mathbf{n}=\mathbf{1 0})\end{array}$ & Percent \\
Health education and promotion & 10 & 100.0 \\
Health management information system & 10 & 100.0 \\
\hline Routine home visits and community outreach & 10 & 100.0 \\
Maternal, Newborn \& Child health care & 10 & 100.0 \\
\hline Family planning & 10 & 100.0 \\
Immunization & 10 & 100.0 \\
\hline Promotion of nutrition \& food education & 10 & 100.0 \\
HIV/AIDS testing and counseling services & 5 & 50.0 \\
\hline Malaria control & 7 & 70.0 \\
Curative care & 10 & 100.0 \\
\hline Essential drugs (regular supply) & 0 & 0.0 \\
Oral health & 0 & 0.0 \\
\hline Community mental health & 0 & 0.0 \\
Referrals & 10 & 100.0 \\
\hline 24 hours services & 0 & 0.0 \\
Maintenance of PHC records & 10 & 100.0 \\
\hline Adolescent health services & 8 & 80.0 \\
\hline
\end{tabular}


lack of basic health care infrastructure, inadequate modern functional facilities and disproportionate health workforce. The government should strengthen PHC by ensuring adequate funding, regular supply of equipment and skilled manpower, which are important determinants of effective provision of health care. This is necessary because PHC is the most inclusive, effective and efficient approach to enhance people's health and well-being, thus ensuring universal health coverage. ${ }^{5}$ The implementation of the Basic Health Care Provision Fund will ensure effective and efficient provision of Basic Minimum Health Care Services that will improve the achievement of universal health coverage. ${ }^{10}$

The poor power supply in all the public PHCs in the LGA will also affect the sustainability of the cold chain system for immunization services. Any negative effect on the immunization coverage could lead to an increase in the incidence of vaccine preventable diseases and mortality among children aged between 0-59 months. A study that assessed PHC System Performance in twelve states in Nigeria had similar findings of poor power supply in $77 \%$ of PHC facilities studied. ${ }^{3}$

Inadequate potable water supply which is core in the Water, Sanitation and Hygiene (WASH) strategy noticed in many PHCs could affect improved sanitation and infection prevention activities in the health facilities such as hand washing, thus increasing the risk of hospital acquired infections among health workers, patients and community members. In addition, all the health facilities lacked sanitary methods of waste disposal. A similar finding was obtained in a study carried out in Zaria, Nigeria. ${ }^{20}$ Poor waste disposal will promote environmental pollution, odour nuisance, aesthetic devaluation of the health facilities, breeding of disease vectors and transmission of communicable diseases.

\section{Limitations of the study}

The data for this study were generated using observational checklist and information from the Heads of the PHCs. Use of Key Informant Interviews of stakeholders such as the Chairman of the LGA, Head of Local Government Administration in the LGA, including the Medical Officer of Health could have assisted in identifying the root causes of the identified challenges and probable ways of mitigating them.

\section{Conclusions}

The PHCs in Egor LGA offered basic healthcare services which were not rendered for 24 hours. Several challenges such as inadequate skilled health personnel, lack of basic amenities, and shortage of essential drugs affect the PHCs. Basic hospital facilities/equipment needed to enhance 24 hours' service delivery at the PHCs should be provided by the Local Government in order to enhance the health and well-being of the people in the LGA thus ensuring universal health coverage.

\section{References}

1. Obionu CN. Primary Health Care for Developing Countries. 3rd edition. Enugu: Evanseenio Printing and Publishing, Enugu, Nigeria. 2016;1-42.

2. Obioha E, Masemote M. Functioning and Challenges of Primary Health Care (PHC) Program in Roma Valley, Lesotho. Studies on Ethno-Medicine 2011;5:73-88. doi:10.1080/ 09735070.2011 .11886393$.
3. Daniel HK, Yanfang SU, Hong W. Assessment of Primary Health Care System Performance in Nigeria: Using the Primary Health Care Performance Indicator Conceptual Framework. Health Syst Reform 2016;2:302-18. doi: 10.1080/23288604.2016.1234861

4. Obembe TA, Osungbade KO, Ibrahim C. Appraisal of Primary Health Care services in Federal Capital Territory, Abuja, Nigeria: How committed are the health workers? Pan Afr Med J 2017;28:134. Available from: https://www.panafrican-medjournal.com/content/article/28/134/full/.

5. Global Conference on Primary Health Care. Declaration of Astana: from Alma - Ata towards universal health coverage and the Sustainable Development Goals. Astana, Kazakhstan, 25-26th October, 2018.

6. Federal Republic of Nigeria and National Primary Health Care Development Agency (NPHCDA). National Guidelines for Development of Primary Health Care Systems in Nigeria. 4th Revised Edition. NPHCDA Abuja, Nigeria. 2012.

7. Federal Government of Nigeria (FGN) and National Primary Health Care Development Agency (NPHCDA). Minimum Standards for Primary Health Care in Nigeria. Department of Planning, Research and Statistics NPHCDA Abuja. 2012;1-69. Available from: https://hfr.health.gov.ng/resources/download/Minimum $\% 20$ Standards $\% 20$ for $\% 20$ Primary $\% 20$ Health $\% 20$ Care $\% 20$ in $\% 20$ Nigeria.pdf

8. Health Partners International. Bringing Primary Health under One Roof. HPI 2014. Available from: http://resources.healthpartners-int.co.uk/resource/bringing-primary-health-careunder-one-roof-prrinn-mnch/.

9. Uzochukwu BSC. Primary Health Care Systems (PRIMASYS): Case study from Nigeria. Geneva: World Health Organization. 2017:1-36. Available from: https://www. who.int/alliance-hpsr/projects/alliancehpsr_nigeriaprimasys. pdf?ua $=1$

10. Federal Republic of Nigeria. National Health Act, 2014, Official Gazette. Government Notice No. 208. Act No. 8. Federal Government Printer, Lagos, Nigeria. 2014;101:A13972.

11. Federal Republic of Nigeria. Second National Strategic Health Development Plan 2018-2022: Ensuring healthy lives and promoting the wellbeing of Nigerian populace at all ages. Federal Ministry of Health, Abuja, Nigeria. 2018.

12. Edo State Government. Strategic Health Development Plan II (SHDP II) 2018-2022: Towards actualizing the provisions of Basic Health Care Services. Edo State Ministry of Health, Benin City, Nigeria. 2018.

13. Abdulraheem IS, Olapipo AR, Amodu MO. Primary health care services in Nigeria: Critical issues and strategies for enhancing the use by the rural communities. J Public Health Epidemiol 2012;4;5-13. Available from: https://academicjournals.org/article/article1379661924_Abdulraheem\%20et\%20al. pdf.

14. Edo State. City Population. Available at: https://www.citypopulation.de/php/nigeria-admin.php?adm1id=NGA012.

15. Oyekale AS. Assessment of primary health care facilities' service readiness in Nigeria. BMC Health Serv Res 2017;17:172. doi:10.1186/s12913-017-2112-8.

16. Alenoghena I, Aigbiremolen AO, Abejegah C, Eboreime E. Primary Health Care in Nigeria: Strategies and Constraints in Implementation. Int J Community Res 2014;3:74-9. Available from: https://www.ajol.info/index.php/ijcr/article/view/ 107665 .

17. Alenoghena IO, Isah EC, Isara AR. Availability and Type of 
Human Resource for Health in Public Primary Health Care Facilities in Selected Communities, Edo State. J Community Med Primary Healthcare 2016;28;11-8. Available from: https://www.ajol.info/index.php/jcmphc/article/view/154689.

18. Adie H, Igbang T, Otu A, et al. Strengthening primary healthcare through community involvement in Cross River State, Nigeria: a descriptive study. Pan Afr Med J 2014;17:221. Available from: https://www.panafrican-med-journal.com/ content/article/17/221/full/.
19. Adam VY, Awunor NS. Perceptions and factors affecting the utilization of health services in a rural community in Southern Nigeria. J Med Biomed Res 2014;13:117-24.

20. Joshua IA, Mohammed S, Makama JG, et al. Hospital waste management as a potential hazard in selected primary healthcare centres in Zaria, Nigeria. Nigerian J Technol 2014;33:215-21. Available from: https://www.ajol.info/ index.php/njt/article/view/107661. 